\title{
New Installations
}

\section{FURTHERING THE NEW IMAGE-THE UNIVERSITY OF LOUISVILLE'S NEW A \& S LEARNING LAB}

by Dale V. Lally Jr.

Upon arriving at the University of Louisville in August 1973, I was handed what amounts to a lab director's dream, namely, the task of designing a new language lab facility to include the latest state of the art in equipment to be installed in the university's brand new Humanities building, scheduled for completion less than a year later. What evolved from that task is the new $A$ \& $S$ Learning Lab which features a complete line of audio and video equipment and even topped off the Humanities building with a set of High Frequency transmitting and receiving antennas.

As put forward by the Department of Modern Languages, the language lab project was favorably received at the upper university levels, particularly since the plan envisioned utilization of the new facilities by the entire University, thereby fulfilling cost effectiveness requirements. After a series of ups and downs, plan revisions, numerous meetings with the University's own superbly competent architects, and a complicated bid process, the actual construction began in early 1975. Strangely enough (but expected) the construction began with a re-construction. Though completed precisely as called for in the original building plans, the space designated for the learning lab was just one very large $\left(55^{\prime} \times 60^{\prime}\right)$ room with almost nothing in it except tile on the floor, a plasterboard ceiling, a few light switches, and a small $\left(13 \times 15^{\prime}\right)$ glassed-in area to serve as a control room. Proper planning required us to rip up much of the tile and cut additional trenches in the concrete slab to accommodate the trench duct system, which was expanded almost three fold over the system called for in the original building plans. And in addition, to comply with the state fire code, the entire ceiling was replaced to permit revamping of the sprinkler system and the addition of banks of incandescent lights controlled by dimmer switches. The latter modification allows us to cut off the flourescents and dim the incandescents thereby enabling students to take notes while viewing visual programs such as slides or motion pictures.

Finally, many new walls of concrete block were constructed to ensure effective acoustic isolation of the various areas of the lab. This massive facelifting took almost three months and 70,000 dollars. Once completed, however, the electronic installation began in earnest and was sufficiently completed in late summer 1975 so that we could use the lab beginning with the Fall 1975 semester. 
Right inside the main entrance, the dutch doors of the Master Control Room (MCR) usually provide the first point of contact for potential users. Naturally the MCR constitutes the real heart of the entire operation. The two lab assistants on duty here oversee the entire operation of the lab. They check out audio and/or video materials, duplicate all manner of audio and video tapes, and make all necessary audio and video patching throughout the facility. Small but highly visible with glass all around, the MCR is the main tie point for a network of invisible audio and video cables extending to all areas of the lab and even to the main AV entity on campus, the Instructional Communications Center, via the campus-wide, underground CATV system.

Most of the MCR equipment, including various SONY open reel and cassette recorders are rack mounted, even the BSR MACDONALD 610 turntable. In general, our master programs are kept on open reel formats and copies are checked out to users in a cassette format. In order to avoid purchasing an open reel duplicator, we specified two SONY TC 756's which operate at $7 \frac{1}{2}$ and 15 i.p.s. In addition, two SONY three motor TC 558's complete the open reel contingent. Cassette mastering is accomplished with a SANYO 4250 deck and with two SONY ER 740 cassettes. However, the real workhorse of our cassette duplication service (which we do at no charge to the students) is the SONY CCP 13 high. speed cassette duplicator. Video dubbing, editing, or off-the-air recording is done with either the PANASONIC NV 3130 open reel VTR or a JVC CRU 6000 videocassette, both of which are drawer mounted in the MCR console. A free standing World Video RV 3201 11" color monitor/receiver completes the video picture. However, the real kicker in the MCR is something rarely found in a language lab control room.

On center stage of the MCR console is a completely equipped amateur radio in the form of a DRAKE TR 4 C, all-band High Frequency transceiver. The antenna systems include a MOSELY TA-33 rotating beam antenna for the 10, 15, and 20 meter bands and a MOSELY vertical antenna for $\mathbf{4 0}$ and $\mathbf{8 0}$ meters. This set-up gives the Learning Lab a two way communications capability with anywhere in the world, a capability dramatically demonstrated during the Guatemalan earthquake disaster in February 1976 when we assisted in passing health and welfare traffic for members of the University and urban community between Louisville and Guatemala City. The majority of the emergency radio traffic was handled on the amateur 20 meter band frequency of $14,325 \mathrm{khz}$. For several days running we monitored and recorded the traffic being passed to and from the disaster area. At one point, a Friday afternoon to be exact, we were monitoring the transmission of an operator in Guatemala City when he suddenly yelled out: "Hey, it's shaking again!" And with those words he suddenly went off the air. Each and every one of us standing in the MCR 
felt our hair standing on end for we knew that at that exact moment, several thousand miles distance, more death and destruction was occuring. After a few minutes which seemed like hours, the operator in Guatemala City came back on again with the news that a severe aftershock had just rocked the city, knocked out the power, and that he was again using his automobile battery to power his transceiver. That was quite an unusual and exciting week to say the least.

We store our AV materials in one of three places. High volume items are kept in a small storage area immediately behind the MCR for immediate checkout. Completely outdated or unused items are kept in our "Cage" room, which is in reality one half of our computer terminal room. Our main/AV library is just a few steps away from the MCR. We have equipped one corner of our AV library with a small working space and a portable recorder to enable faculty members to preview our tapes for possible classroom utilization.

Next to our AV library is the nearest thing we have to a classic language lab-but we call it the Electronic Classroom (ECR). Along the walls are a total of 24 audio-active-record-compare (phase 3) carrels, with 18 Visual Educom 903 open reel recorders and 6 SONY cassette recorders. Though the individual student positions do not possess video monitors, we have a video capability in the form of 2 RCA monitor/receivers mounted on opposite walls. In one corner is the teacher console equipped with a turntable, 2 open reel and 2 cassette audio sources and a drawer mounted SONY VO 1800 videocassette. Tucked away in one corner of the console is a telephone plug-in for future computer classes. At the far end of the room, opposite the console, is the enclosed projection booth from whence motion pictures, slides and filmstrips can be projected, with remote control from the teacher console if desired. The flourescents and the incandescent dimmer switches can be controlled either from behind the teacher console or from the projection booth. Finally, the room's video capability has been further enhanced through the installation of an additional video camera input jack on the front of the projection booth, connected to the SONY VO $\mathbf{1 8 0 0}$ in the teacher console via underground coaxial cable. This remote camera jack permits videotaping in the room without the annoyance of cables scattered about the floor.

From the rear of the ECR a door leads into the adjacent Seminar Room (SR). Though less than 300 square feet in area, it is perfect for small group presentations and committee meetings. The SR is equipped with the same lighting system to dim the incandescents for slide and motion picture viewing. A telephone plug-in jack, a wall mounted PIONEER speaker and a wall mounted WORLD VIDEO monitor/receiver conected via the MCR to the University's CATV system were also included.

Next to the Seminar Room is another area made even more versatile through an internal division of space. Originally a room of about $14^{\prime} \times 18^{\prime}$, 
we were able to convert this area into two separate spaces through the erection of a wire mesh partition and locking door across the width of the room. On the one hand, the area behind the wire mesh (which we call the "Cage") is a storage area for completely outdated tapes and our portable AV equipment, which are further secured in locking cabinets. Since the remaining half of the room has three computer terminals, one hardcopy and two CRT for use by the computer students (and eventually for the foreign language students when we go to CAl language instruction), we call this area simply the Computer Room (CR). We keep the door to this area closed so that the terminal users can talk without annoying the lounge or independent study areas immediately adjacent.

The A \& S Learning Lab lounge forms the geometric center of the installation and offers comfortable seating and working space for about $\mathbf{3 0}$ people. The two PIONEER speakers mounted on the wall deliver FM background music to the area. We have also provided a magazine rack filled with foreign language periodicals, the majority of which are outdated editions supplied to us on a semi-regular basis by the Reference section of the University's main library.

Right next to and easily accessible from the lounge is the Independent Study Area (ISA) with a total of 19 carrels. Designed to fulfill a basic language lab audio-active-record-compare function, each and every carrel is equipped with a SONY open reel or cassette student rccorder. Two carrels are also equipped with SINGER Auto Advance filmstrip projectors, while two more have SINGER Caramate slide projector/audio tape players. Five of the 19 carrels are extra wide $\left(36^{\prime \prime}\right)$ and feature JVC videocassette player/recorders and WORLD VIDEO 9" monitor/receivers. Using a quick and easy check-out procedure, users may obtain audio and/or visual materials for use in the lab. However, to increase exposure, we do furnish a free duplicating service. We merely ask users of this service to supply their own tape and fill out a short request form.

From the date of opening in September 75 to mid-April 76, we counted over 48,000 users in the lab. We arrived at this figure simply by counting the people in the facility every hour on the half hour, with the ECR counted separately. We were able to count the ECR separately because of a separate console log which is filled out by anyone using the ECR. During the period indicated we made 1886 tape duplications, checked out over 5,000 audio and/or visual programs, and saw almost 3,000 users in the ECR.

The students using the lab came from the departments of Modern Languages, Psychology, History, Math and Sociology. However the latest addition to the user list is the University's International Center, which schedules TESOL/classes into the ECR on a regular basis. And the foreign students studying English as a second language constitute far and away the single most enthusiastic group in the lab. On many an evening every 
single one of our video carrels have been occupied by the foreign students watching off-the-air TV. Some of these students regularly check out blank videocassettes, record portions of popular TV shows, and replay them for increased comprehension. The american foreign language students could certainly learn something from the foreign students since the Learning Lab currently has a collection of popular american TV shows synchronized into French, German, and Spanish for overseas distribution. Included in this collection are HAWAll 50, THE WORLD OF DISNEY, SPACE 1999, MANHUNT and GUNSMOKE. During the past two years, several of the German versions were successfully integrated into Intermediate German courses taught by the author. Nevertheless, the vast majority of the programs used are audio tapes. However, there is quite a bit of diversity even among the audio tapes which is basically a function of the tape source.

Most of the tapes used in the Learning Lab were acquired to accompany the various foreign language texts, often at no cost. Another source of tape materials are the faculty members themselves. Quite a few teachers have collections of foreign songs which are integrated right into the course. Even foreign language versions of well known american pop songs have been successfully employed in both German and French classes since the melodies are well known by the students. Another source of audio programs is connected with our amateur radio station.

Right next to the DRAKE TR4C transceiver in the MCR is a DRAKE SPR4 all band communications receiver which we use to record foreign language shortwave broadcasts. It became necessary to purchase this extra piece of equipment since the receiver section of the transceiver would not tune the international shortwave frequencies. Every day, Monday through Friday, we record German, French, and Spanish news broadcasts onto audio cassettes and check them out to interested individuals. We dedicate a cassette to each day of the week and thus, at any one time, will have at least five days of news in the three major languages.

Staffing for the Learning Lab consists of one full-time professional and a crew of lab assistants. The lab is normally open from 40 to 80 hours per week depending upon the pool of lab assistants, and ultimately upon the availability of federal work-study funds.

During this first year of operation, we have run countless tours through the lab for visiting teachers and students. The comment heard most often from these visitors concerns the immense versatility of the lab. The major objectives in the lab design were expansion potential and universality.

The expansion potential was enhanced by measured overinvestment in audio and video cables. In the past, many otherwise excellent systems have been seriously impeded simply because of insufficient provision for future expansion of signal paths within the facility. In the A \& S Learning 
Lab, every position, every room, every potential working space was provideo with audio and video cables-and even spare pairs. Admittedly, were we to use every single pair and cable, there would be little room to stand up. But one of the design considerations was, "It is far better to have it and not need it, than to need it and not have it!" And the expense of pulling in audio and video cables during initial construction is miniscule when compared to the cost of trying to force additional wire through existing, partially filled conduits. It is certainly much more cost effective to fill them at the very outset.

The objective of universality means simply that the lab can be used to teach just about anything which can be recorded. To accomplish this we have provided a limited capability of many diverse modes and included audio and video tapes, 8 and $16 \mathrm{~mm}$ motion pictures, filmstrips, slides, and computer terminals. When something new comes down the pike, we will have a space and a wire for it. Certainly the only genuine inhibiting factor in the University of Louisville's A \& S Learning Lab is one's imagination! 